\title{
CORDÕES DE SOLDA DE NIÓBIO TRATADOS TERMICAMENTE VIA IMPLANTAÇÃO IÔNICA POR IMERSÃO EM PLASMA
}

\author{
Aline Capella de Oliveira ' \\ Maria Fernanda Gonçalves de Oliveira ' \\ Denis Angelo da Silva ' \\ Rogério Moraes Oliveira ${ }^{2}$ \\ Rudimar Riva ${ }^{3}$
}

\section{Resumo}

Cordões de solda em nióbio, obtidos pela tecnologia laser, receberam tratamento térmico via implantação iônica por imersão em plasma (3IP) de nitrogênio, para formação de camadas de nitretos sobre a superfície do material. O tratamento 3IP foi realizado em temperaturas entre $1000-1200^{\circ} \mathrm{C}$ por I h. Resultados mostram significativa alteração na superfície do material, em termos de composição química, evidenciando a formação de nitretos de nióbio sobre esta superfície. Em geral, os nitretos de materiais refratários apresentam propriedades desejáveis para aplicações que envolvem temperatura elevadas de trabalho como: estabilidade térmica, elevado ponto de fusão e boa resistência à oxidação. Em virtude do aquecimento do substrato, durante o tratamento térmico, observam-se alterações microestruturais no material tratado e consequente homogeneidade dos valores de dureza em suas diferentes regiões: cordão de solda, zona termicamente afetada (ZAC) e material de base

Palavras-chave: Nióbio; 3IP; Nitreto de nióbio; Soldagem a laser.

\section{NIOBIUM WELD SEAMS HEAT TREATED BY PLASMA BASED ION IMPLANTATION}

\begin{abstract}
Niobium weld seams performed by laser technology, have received nitrogen plasma based ion implantation (PBII) to nitride formation on the material surface layers. The treatment was performed in temperature range of $1000-1200^{\circ} \mathrm{C}$ for Ih. Results show a significant change of the chemical composition in the material surface, with the presence of niobium nitrides in this region. In general, nitrides of refractory materials have desirable properties for applications involving high temperature working such as: thermal stability, high melting point and good oxidation resistance. Due to the substrate heating during the heat treatment, it was observed microstructural changes of the treated material with homogeneity of hardness values in different regions: weld bead, heat affected zone (HAZ) and base material.
\end{abstract}

Keywords: Niobium; PBII; Niobium nitrides; Laser welding.

\section{INTRODUÇÃO}

O nióbio $(\mathrm{Nb})$ é um metal refratário com aplicações no setor aeroespacial, em componentes de motores foguetes, especialmente devido à sua elevada temperatura de fusão, $2468^{\circ} \mathrm{C}$ [I]. No Brasil, o Laboratório de Combustão e Propulsão do Instituto Nacional de Pesquisas Espaciais (LCP/INPE) tem utilizado o nióbio puro para fabricação de tubeiras de motores foguetes de múltiplos estágios, no estudo do desempenho e análises térmicas de propulsores bipropolentes [2].

O Brasil detém praticamente o monopólio de nióbio, $98 \%$, cujas jazidas encontram-se em maior concentração no estado de Minas Gerais [3], mas sua utilização no estado puro ainda é pouco explorada pelo setor aeroespacial. Isso porque, um dos aspectos relevantes na utilização de metais refratários,

'Instituto de Ciência e Tecnologia, Universidade Federal de São Paulo - Unifesp, São José dos Campos, SP, Brasil. E-mail: aline.capella@unifesp.br

${ }^{2}$ Laboratório Associado de Plasma, Instituto Nacional de Pesquisas Espaciais - INPE, São José dos Campos, SP, Brasil.

${ }^{3}$ Divisão de Fotônica, Instituto de Estudos Avançados, São José dos Campos, SP, Brasil. 
em temperaturas elevadas, é sua acentuada reatividade com o oxigênio, aspecto intrínseco ao fenômeno de combustão presente em motores foguetes. Especificamente, o nióbio apresenta reação com o oxigênio em temperaturas próximas a $200^{\circ} \mathrm{C}$ [I]. Tal comportamento pode degradar suas propriedades mecânicas, comprometendo seu desempenho nestas aplicações. A utilização da tecnologia laser no processo de união de metais e ligas apresenta características únicas de versatilidade, confiabilidade, velocidade, automação e alta precisão [4]. As propriedades da coerência espacial, que permite a focalização da luz em pequenas dimensões, e a alta densidade de energia, que fornece uma intensidade de radiação localizada e extremamente elevada, são as bases de suas vantagens sobre métodos tradicionais de processamento de materiais [4]. Mas a oxidação do nióbio também pode influenciar negativamente nos diferentes processos de junção deste material, tanto pela formação de defeitos na região de junção como na redução ou perda de suas propriedades mecânicas após interação com a fonte de calor [5].

Para minimizar o efeito da oxidação de metais refratários, camadas protetivas têm sido empregadas nas superfícies destes materiais [6]. Em particular, nitretos de metais refratários apresentam propriedades desejáveis como: estabilidade térmica, elevada dureza e baixas taxas de desgaste e corrosão. Em contato com a atmosfera ambiente, os nitretos de nióbio oxidam-se a partir de temperaturas acima de $800^{\circ} \mathrm{C}[6]$.

Uma tecnologia disponível para formação de camadas protetivas é a implantação iônica por imersão em plasma (3IP). A técnica consiste no bombardeamento de um material sólido com átomos ionizados de média e alta energia. Essa técnica oferece a possibilidade de se implantar, ou ligar, qualquer tipo de elemento nas regiões próximas da superfície do material [7], modificando as características mecânicas, físicas ou químicas na região superficial do material. A alteração nas propriedades do substrato se deve à transferência de energia dos íons para sua superfície e à diversidade de espécies químicas presentes no plasma [7]. No 3IP, o material a ser tratado é imerso no plasma, sendo submetido a pulsos negativos de média a alta tensão (tipicamente $5 \mathrm{kV}$ a $50 \mathrm{kV}$ ), duração de $10 \mu \mathrm{s}$ a $100 \mu$ s e taxa de repetição variando entre $10 \mathrm{~Hz}$ a $5 \mathrm{kHz}$ [8]. Resultados promissores foram obtidos, em termos de formação de nitretos de nióbio nas camadas mais superficiais do metal, promovendo melhorias em suas propriedades mecânicas e tribológicas [I].

O presente trabalho tem como objetivo estudar a viabilidade de realizar cordões de solda de nióbio puro, utilizando a tecnologia laser, avaliando o comportamento do conjunto soldado após tratamento térmico subsequente via 3IP. Embora nitretos de nióbio tenham sido obtidos pela tecnologia 3IP [I], a formação dessa camada, como barreira protetora, na região de junção do material não tem sido explorada.

\section{MATERIAIS E MÉTODOS}

Chapas de nióbio puro, com dimensões de $20 \mathrm{~mm} \times 100 \mathrm{~mm}$ e 3,0 mm de espessura, foram utilizadas no estudo. Análise realizada por meio de espectroscopia por energia dispersiva de raios $X$ (EDS, JEOL, modelo JSM-53 I0) foi conduzida para identificação dos elementos químicos presentes no material.

Primeiramente, as amostras foram submetidas ao processo de soldagem a laser em geometria bead-on-plate, no Laboratório de Desenvolvimento e Aplicações de Lasers e Óptica (DedALO) do Instituto de Estudos Avançados (IEAv-DCTA). Para isso, a amostra foi fixada sobre uma mesa XYZ CNC de processo e ensaios foram conduzidos utilizando um laser contínuo de Yb:fibra com $2 \mathrm{~kW}$ de potência máxima. Utilizando uma lente com distância focal de $160 \mathrm{~mm}$, o feixe foi focalizado em uma área de $100 \mu \mathrm{m}$ de diâmetro sobre a superfície da amostra. A cabeça de processamento do laser foi posicionada considerando um ângulo $3^{\circ}$ em relação à superfície da amostra. Gás hélio, com fluxo de 20 L/min, foi utilizado como gás de proteção no processo em todas as condições experimentais. Os ensaios foram conduzidos variando-se a potência média do laser e as velocidades de processo, conforme descrito na Tabela I.

A partir dos ensaios experimentais realizados, seções transversais do cordão de solda foram analisadas em termos dimensionais e microestruturais por microscopia óptica. Para isso, amostras foram cortadas e embutidas em baquelite. Em seguida suas superfícies foram lixadas (lixas d'água de SiC com granulação de 240, 400, 600 e 1200 , respectivamente) e polidas em solução de alumina de I $\mu \mathrm{m}$. Para revelação da microestrutura do material, as superfícies foram submetidas a ataque eletrolítico, com solução de $60 \mathrm{~mL}$ de ácido fluorídrico e $20 \mathrm{~mL}$ de ácido nítrico, aplicando uma tensão de $4 \mathrm{~V}$ por aproximadamente 5 segundos. Análises metalográficas das regiões: zona de fusão (ZF), zona termicamente afetada pelo calor (ZAC) e material de base, foram feitas utilizando um microscópio óptico (Zeiss, modelo Axiolmager $\mathrm{A} 2 \mathrm{~m}$ ).

Amostras soldadas, em diferentes condições experimentais, foram cortadas em dimensões de $20 \mathrm{~mm} \times 25 \mathrm{~mm}$ para realização do tratamento 3IP. O tratamento de implantação iônica por imersão em plasma (3IP) foi realizado no Laboratório Associado de Plasma do INPE. Para isso, a amostra foi inserida em uma câmara de vácuo. A fim de assegurar a limpeza superficial do metal, foi realizado um bombardeamento prévio sobre a amostra com

Tabela I. Condições experimentais utilizadas no processo de soldagem a laser

\begin{tabular}{|c|c|c|c|c|c|c|c|c|c|}
\hline \multirow{2}{*}{$\begin{array}{c}\text { Potência }(\mathrm{W}) \\
\text { Velocidade }(\mathrm{mm} / \mathrm{s})\end{array}$} & \multicolumn{3}{|c|}{1000} & \multicolumn{3}{|c|}{1500} & \multicolumn{3}{|c|}{800} \\
\hline & 100 & 50 & 75 & 50 & 75 & 100 & 50 & 75 & 100 \\
\hline
\end{tabular}


íons de argônio (Ar), utilizando uma tensão de $5 \mathrm{kV}$ durante 10 minutos. Em seguida, ensaios de 3IP em atmosfera de nitrogênio foram conduzidos em pressão de trabalho entre 3,0 mbar e 4,0 mbar. As demais condições experimentais estão descritas na Tabela 2. Devido ao aquecimento do substrato, o porta-amostra foi polarizado positivamente $(50 \mathrm{a} / 00 \mathrm{~V})$, durante o intervalo de tempo em que o pulso de alta tensão permanece desligado, como o objetivo de atrair elétrons, emitidos por um catodo óxido, em direção à amostra para seu respectivo aquecimento (Figura I).

O levantamento das fases e da composição química presentes na superfície das amostras, submetidas ou não ao tratamento 3IP, foi realizado por meio de difratometria de raios $X$ (DRX Panalytical - modelo x' Pert Powder), considerando uma varredura entre ângulos $(2 \theta)$ entre $20^{\circ}$ e $120^{\circ}$. Após a obtenção do espectro, análises dos picos foram feitas por meio do software PANalytical, a partir da comparação entre cartas espectrais padrões.

Ensaios de dureza Vickers foram realizados nas seções transversais de amostras soldadas, submetidas ou não ao tratamento 3IP, considerando diferentes regiões da amostra: zona de fusão, zona afetada pelo calor e material base. A caracterização foi realizada em um microdurômetro (Shimadzu, modelo HMV-2), considerando carga constante de 25gf.

\section{RESULTADOS E DISCUSSÕES}

A Tabela 3 apresenta os dados obtidos por EDS dos elementos químicos presentes no material utilizado no trabalho. O nióbio, considerado comercialmente puro, apresenta como principais elementos contaminantes 0 silício e o cobre, resultado do processo de obtenção e processamento do metal

Após a realização do procedimento experimental, as características dimensionais do cordão foram analisadas em função da variação dos parâmetros de processo, e estão apresentadas nas Figuras 2 e 3 . Observa-se que os cordões de solda apresentam maiores valores de profundidade de penetração seja com a redução da velocidade de processo, considerando uma potência média constante, ou com o aumento da potência média aplicada, em velocidade fixa. Este aspecto está associado à quantidade de energia entregue em função da variação dos parâmetros, que é efetivamente absorvida pelo material durante o processo de soldagem. É possível observar comportamento similar em relação à largura no topo do cordão de solda, com redução do seu valor pelo aumento da velocidade de processo, ou diminuição da potência média aplicada. Por outro lado, a variação da largura do cordão nas regiões central e na raiz aproxima-se de um valor constante com a variação dos parâmetros de processo. Isso porque, uma vez que o calor gerado no

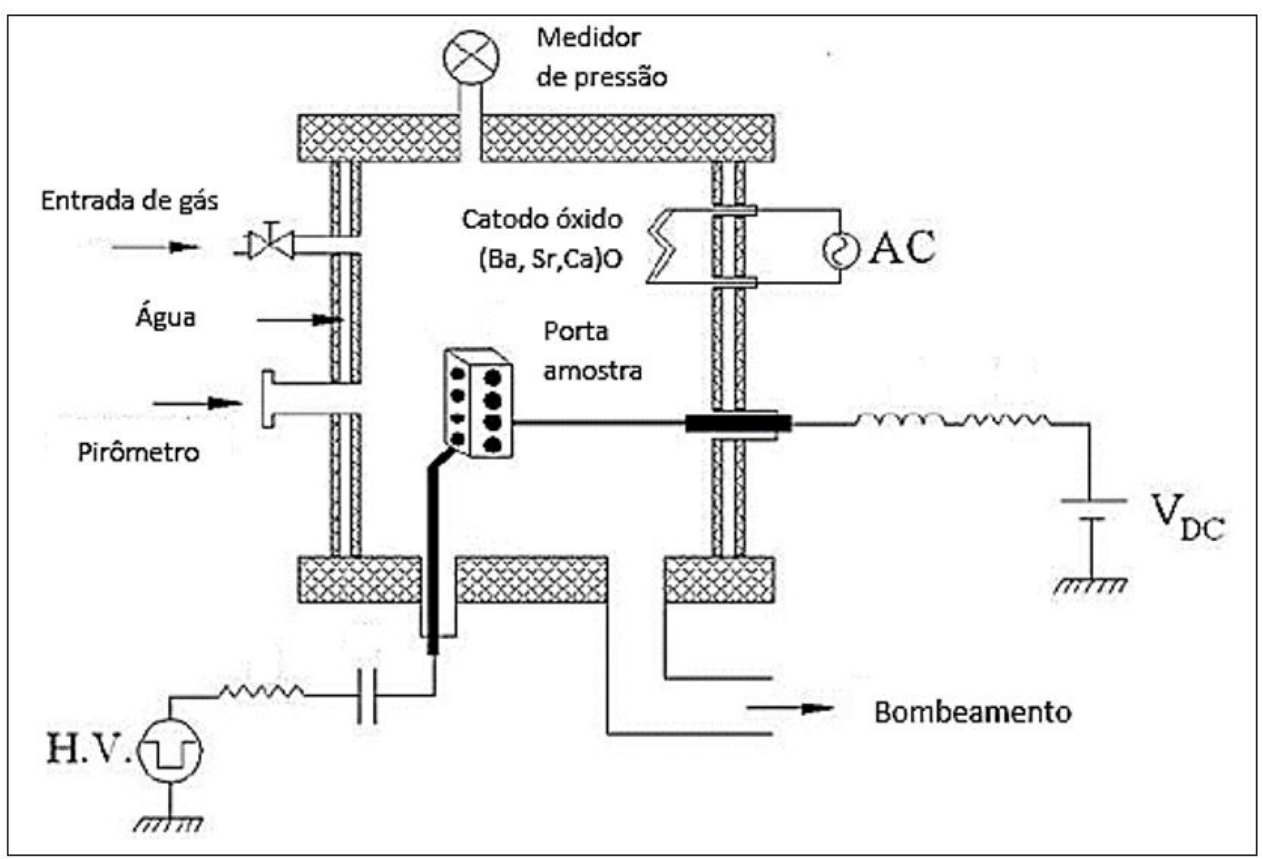

Figura I. Aparato experimental utilizado para tratamento 3IP em temperatura controlada [I].

Tabela 2. Condições experimentais consideradas no tratamento 3IP

\begin{tabular}{ccccccc}
\hline \multirow{2}{*}{ Amostra } & \multicolumn{3}{c}{ Dados do pulso negativo } & Temperatura do & $\begin{array}{c}\text { Tempo de } \\
\text { substrato }\end{array}$ & tratamento \\
\cline { 2 - 5 } & Frequência & Largura & Tensão & & $1000^{\circ} \mathrm{C}$ & 1 hora \\
IT & $400 \mathrm{~Hz}$ & $30 \mu \mathrm{sV}$ & $8 \mathrm{kV}$ & & $1200^{\circ} \mathrm{C}$ & $1 \mathrm{hora}$ \\
\hline
\end{tabular}

Tecnol. Metal. Mater. Miner., São Paulo, 
material, com a absorção de energia do feixe, é transferido para o material por condução térmica, a região de interação neste volume está limitada ao comprimento de difusão térmica do material (ou difusividade térmica). Essa medida, está relacionada com a condutividade térmica do material e com a velocidade do processo, sendo independente da potência do laser empregada [9].

$\mathrm{Na}$ zona afetada pelo calor (ZAC), a variação nos parâmetros de processo não influencia sua característica dimensional, sendo da ordem de $10 \pm 2 \mu \mathrm{m}$ em todas as condições analisadas. Embora o aporte térmico não seja constante, considerando a variação dos parâmetros de processo, a dimensão da ZAC não é influenciada por esta variação uma vez que sua extensão é medida a partir do término da zona fundida do material, ou cordão de solda.

Tabela 3. EDS de amostra padrão do nióbio

\begin{tabular}{cc}
\hline Elemento & \% Peso \\
\hline Nióbio $(\mathrm{Nb})$ & 91,9 \\
Silício $(\mathrm{Si})$ & 4,48 \\
Cobre $(\mathrm{Cu})$ & 3,63 \\
\hline
\end{tabular}

Ou seja, como no limiar entre a zona fundida e a ZAC, a temperatura atingida é da ordem da temperatura de fusão do material, a quantidade de energia conduzida para $\circ$ volume do material decresce em função da temperatura, até $\circ$ limite de sua extensão, onde o material apresenta temperatura ambiente.

As Figuras 4a, b comparam o espectro obtido da superfície de amostra soldada sem tratamento 3IP (Figura 4a), com o espectro obtido da superfície do material soldado e submetido posteriormente ao tratamento de 3IP (Figura 4b). É possível observar a formação de nitretos de nióbio na superfície do material tratado, com maior incidência de nitretos do tipo $\mathrm{Nb}_{2} \mathrm{~N}$ (PDF-ICDD 00-020-0802), embora nitretos do tipo $\mathrm{Nb}_{4} \mathrm{~N}_{5}$ (PDF-ICDD $0 \mathrm{I}$-074-0606) também estejam presentes.

Imagens da seção transversal do cordão de solda, obtidas por microscopia óptica, estão apresentadas nas Figuras 5, 6 e 7, considerando amostras sem tratamento e submetidas ao tratamento de 3IP, em diferentes condições experimentais. Observa-se na amostra soldada sem tratamento (Figura 5) significativa variação na microestrutura do material em relação às regiões de fusão $(Z F)$, zona afetada pelo calor (ZAC) e material base. Tanto na ZF quanto na ZAC,

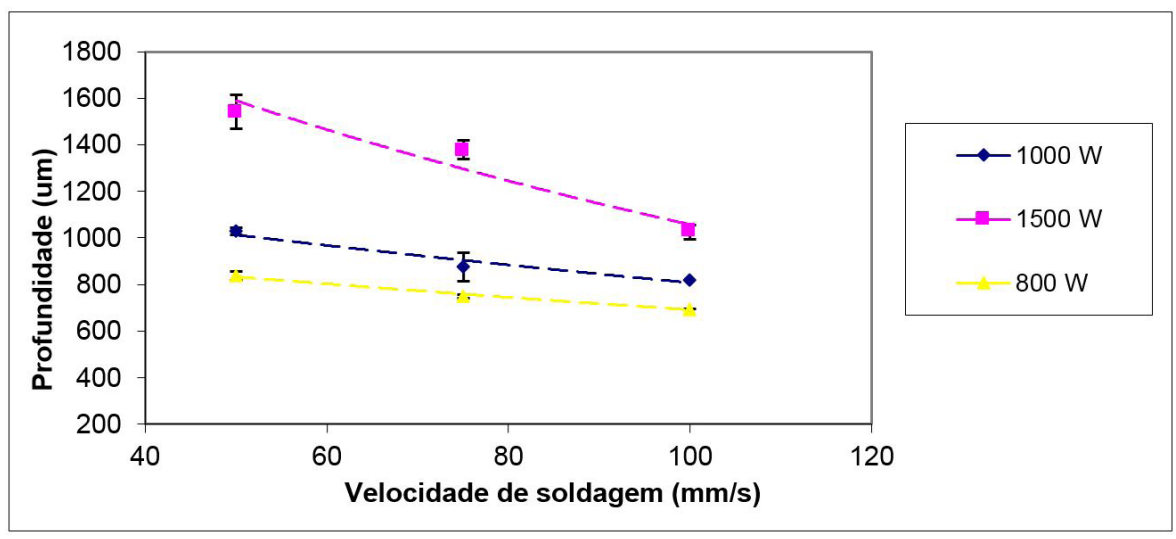

Figura 2. Profundidade de penetração do cordão de solda de Nb em função da velocidade de processo.

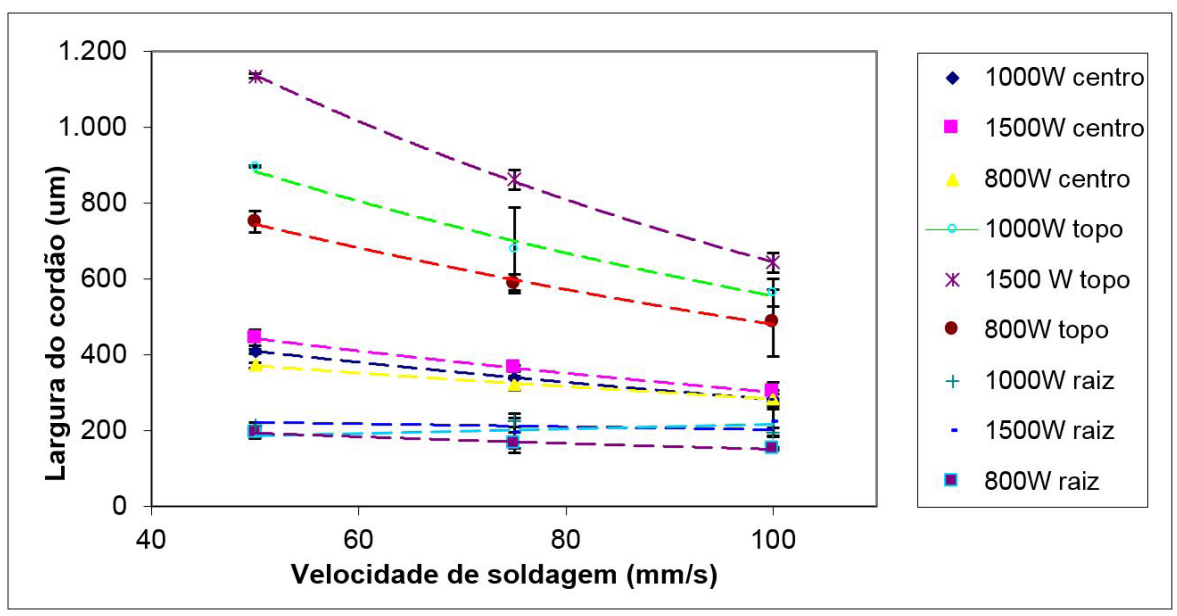

Figura 3. Largura do cordão de solda de $\mathrm{Nb}$ em função da velocidade de processo. 

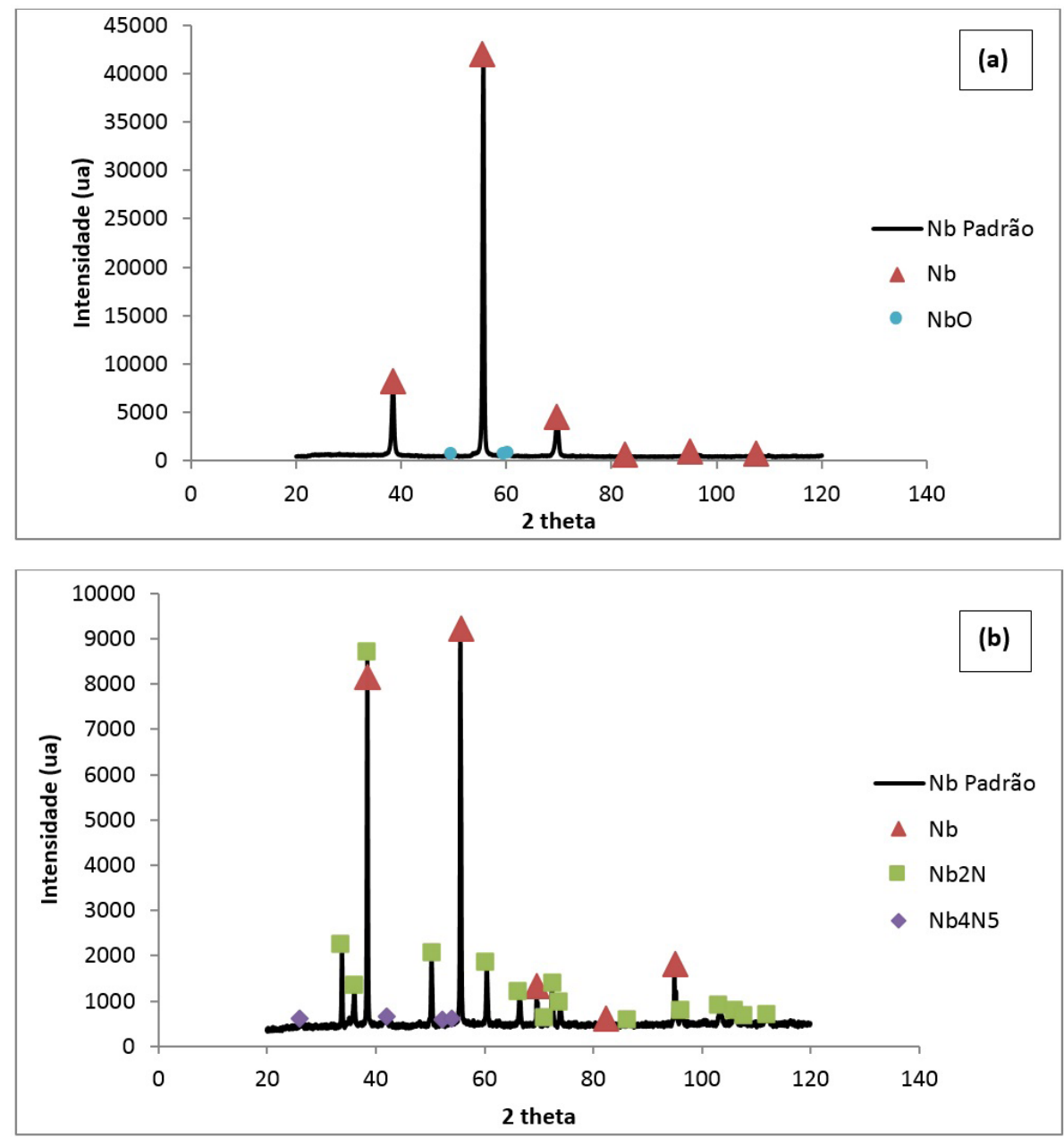

Figura 4. Espectros de $\mathrm{DRX}$ da superfície de amostras de nióbio (a) sem tratamento térmico e (b) submetida ao tratamento $3 \mathrm{IP}$ a $1000^{\circ} \mathrm{C}$.

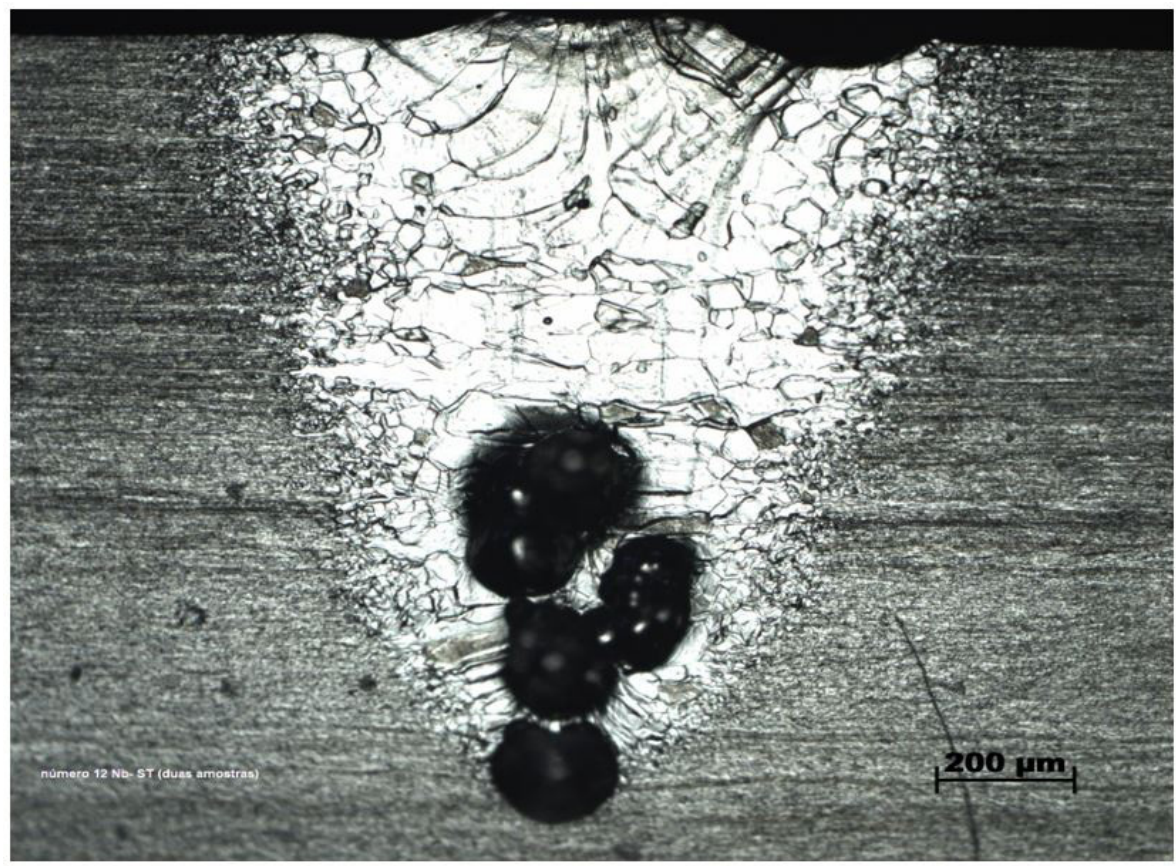

Figura 5. Seção transversal do cordão de solda de $\mathrm{Nb}$.

Tecnol. Metal. Mater. Miner., São Paulo, 
a recristalização do material é obtida após a interação do feixe de laser com o material. Já na região do material de base, a metalografia apresenta micrografia característica do processo de laminação a frio do material, a partir de sua fabricação. Esse aspecto, entretanto, não é observado nas amostras soldadas e submentidas posteriormente ao tratamento de 3IP (Figuras 6 e 7). Nestes casos, observa-se a presença de grãos finos equiaxiais, tornando a microestrutura nas diferentes regiões: ZF, ZAC e do material base, mais homogênea, dificultanto inclusive a identicação das fronteiras entre estas regiões. Este comportamento está diretamente relacionado ao aquecimento do substrato durante o processo de implantação iônica, onde as temperaturas de aquecimento alcançaram entre $1000^{\circ}$ e $1200^{\circ} \mathrm{C}$, muito próximas temperutura de recristalização do nióbio, da ordem $1050^{\circ} \mathrm{C}$. É importante ressaltar que se o substrato

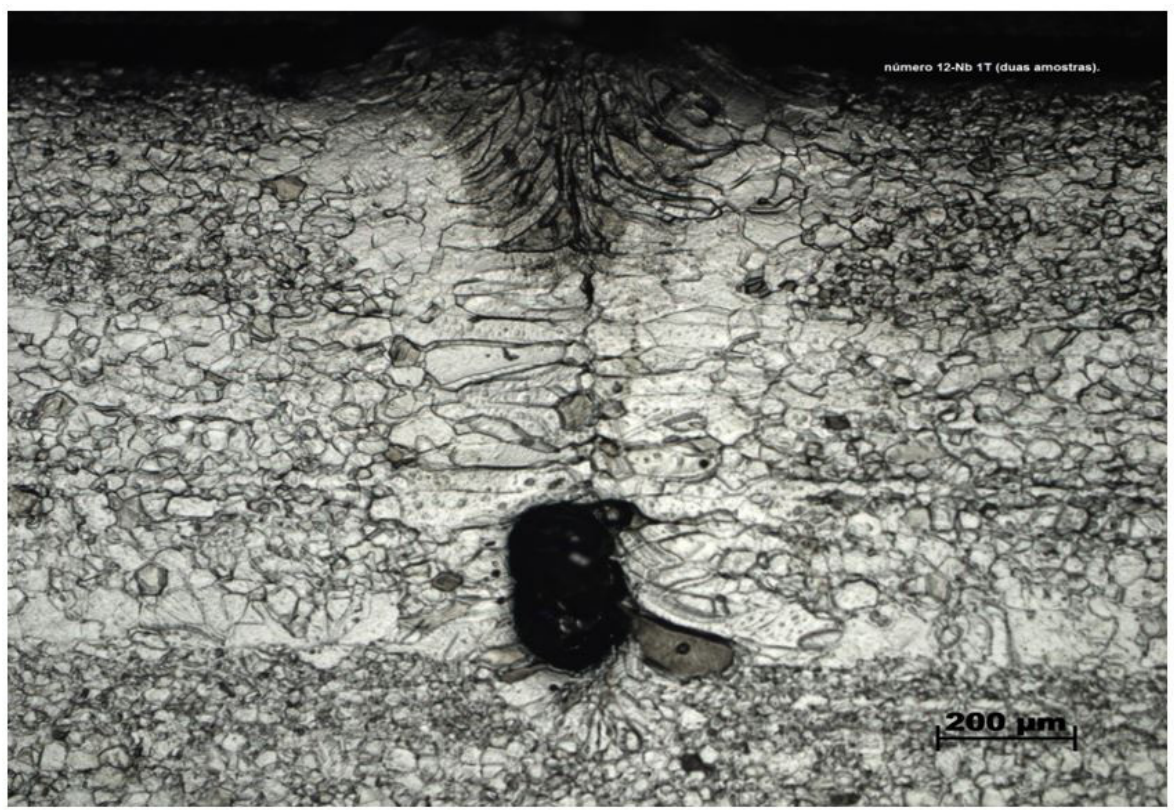

Figura 6. Seção transversal do cordão de solda de $\mathrm{Nb}$ tratado via $3 \mathrm{IP}$ a $1000^{\circ} \mathrm{C}$.

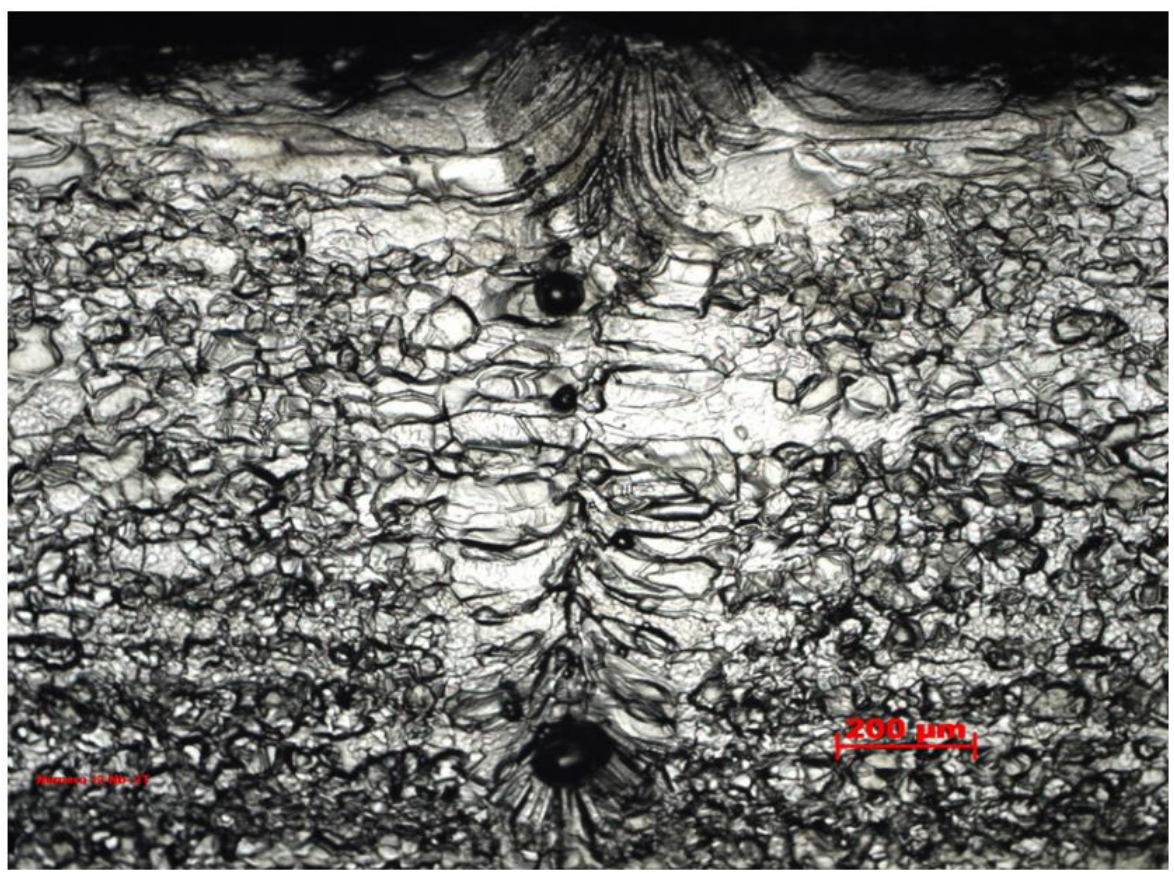

Figura 7. Seção transversal do cordão de solda de $\mathrm{Nb}$ tratado via $3 \mathrm{IP}$ a $1200^{\circ} \mathrm{C}$. 


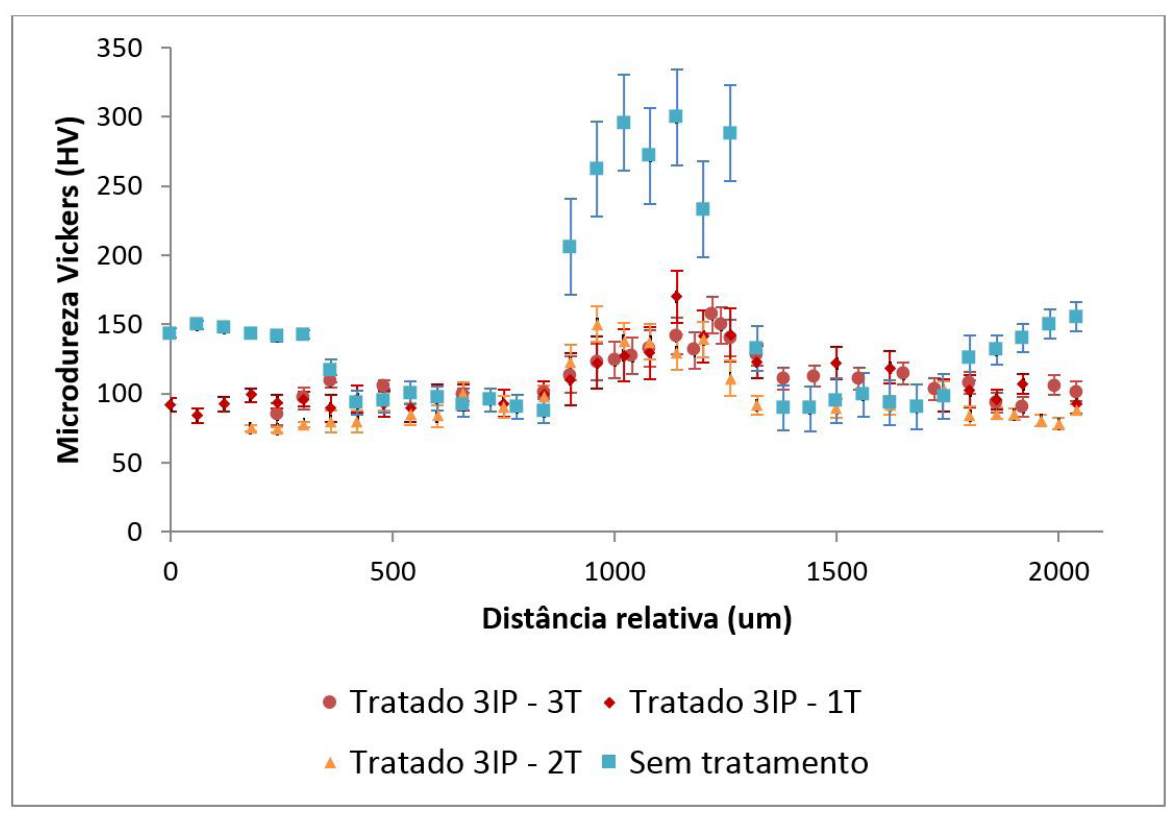

Figura 8. Microdureza Vickers de amostras soldadas com e sem tratamento térmico de 3IP.

não fosse aquecido durante o tratamento de 3IP (processo 3IP convencional), a recristalização do material de base não seria observada.

A presença de defeitos, como poros no cordão de solda, pode ser atribuída a diferentes aspectos, dentre eles, a presença de oxigênio na superfície do material durante o processo de soldagem, aspecto evidenciado nos resultados de DRX da amostra (Figura 4a). Ou ainda, pela instabilidade do processo, uma vez que se trata de uma soldagem por penetração que é fortemente influenciada pelos parâmetros escolhidos. Neste sentido, o melhor preparo da superfície do material, para posterior procedimento de soldagem, e a escolha de parâmetros otimizados de processo podem contribuir para minimização da presença destes defeitos.

Os efeitos da variação de dureza, de amostras soldadas e submetidas ao tratamento 3IP, foram avaliados nas diferentes regiões do cordão de solda e material de base (Figura 8). Observa-se que, comparado a amostra soldada sem tratamento, as amostras tratadas via 3IP apresentam valores de dureza mais homogêneos nas diferentes regiões: ZF, ZAC e material de base, entre 100 e $150 \mathrm{HV}$. É possível observar ainda, a diminuição da dureza na região de base em amostras submetidas ao tratamento de 3IP, comparado ao material de base sem o tratamento. Isso ocorre devido à recristalização do material nesta região, que apresenta o fenômeno de encruamento em seu estado original (como fabricado).

Valores de dureza mais homogêneos podem ser benéficos na resistência mecânica do conjunto soldado quando este é submetido a esforços de tração uniaxial, por exemplo. Isso porque cordões de solda gerados com diferença significativa de dureza, se comparado ao material de base, podem dar origem a campos de concentrações de tensões residuais entre estas regiões, gerando detrimento da resistência mecânica do conjunto soldado, Neste sentido, embora a perda de dureza possa reduzir as propriedades tribológicas do material, e a recristalização deste, possa reduzir o limite de escoamento do material, espera-se um aumento no limite de resistência mecânica do conjunto soldado, pela homogeneização dos valores de dureza nas diferentes regiões de interação. Ensaios posteriores serão realizados na segunda etapa do projeto, de modo a avaliar tal comportamento.

\section{CONCLUSÕES}

Dos resultados obtidos é possível concluir a eficiência do tratamento 3IP na formação de nitretos de nióbio superficiais. Além disso, o tratamento posterior ao processo de soldagem induz a recristalização do material, fazendo com que as diferentes regiões do material soldado: zona de fusão, zona afetada pelo calor e material base apresentem uma microestrutura mais homogênea. Esse aspecto influencia no comportamento mecânico do material, em termos de variação de dureza, onde valores entre $100-150$ HV são obtidos. Tal comportamento pode influenciar na melhoria das propriedades de resistência mecânica do conjunto soldado.

\section{Agradecimentos}

Os autores agradecem ao CNPq pelos auxílios financeiros concedidos para a realização deste trabalho (PIBIC-INPE $n^{\circ}$ I 297 I 0/20 I3-0 e PIBIC-IEAv n 134972/20 I3-9). 


\section{REFERÊNCIAS}

I Oliveira RM, Oliveira AC, Carreri FC, Gomesa GF, Ueda M, Silva MMNF, et al. Detailed surface analyses and improved mechanical and tribological properties of niobium treated by high temperature nitrogen plasma based ion implantation. Applied Surface Science. 2013;283:382-388.

2 Salles CE, Serra AM Jr. Medidas de desempenho e análise térmica de um propulsor bipropelente de $200 \mathrm{~N}$ de empuxo. V CONGRESSO NACIONAL DE ENGENHARIA MECÂNICA; 2008 Ago 25-28; Salvador, Brasil. Rio de Janeiro: ABCM; 2008. p. I-7 [acesso em 5 mar. 2014]. Disponível em: http://mtcm /8.sid.inpe.br/col/sid.inpe.br/ mtcm I8\%4080/2008/I2.19.13.10/doc/medidas.pdf.

3 Branco PM. O nióbio brasileiro. Brasília: CPRM; 2014 [acesso em 22 jan. 2014]. Disponível em: http://www.cprm. gov.br/publique/cgi/cgilua.exe/sys/start.htm?infoid $=2616 \&$ sid $=129$

4 Cao X, Jahazi M, Immarigeon JP, Wallace W. A review of laser welding techniques for magnesium alloys. Journal of Materials Processing Technology. 2006; 171:188-204.

5 Scott MH, Knowlson PM. The welding and brazing of the refractory metals niobium, tantalum, molybdenum and tungsten. Journal of the Less Common Metals. 1963;5:205-244.

6 Borcz, C. Estudo do processo de nitretação por plasma de nióbio [acesso em 2 fev. 20l4]. Disponível em: http:// www.pgmec.ufpr.br/dissertacoes/dissertacao_I I3_claudio_borcz.pdf

7 Anders A. From plasma immersion ion implantation to deposition: a historical perspective on principles and trends. Surface and Coatings Technology. 2002;156:3-12.

8 Pinto AEA, Tabacniks MH. Implantação iônica.São Paulo: Instituto de Física da USP - Laboratório de Materiais e Feixes lônicos; 2002. Relatório técnico.

9 Lima MSF, Riva R, Oliveira AC, Siqueira GR. Laser beam welding aerospace aluminum using fiber lasers. Proceedings of SPIE. 2009:7|3|:12-18.

Recebido em: 4 Dez. 2015

Aceito em: 2I Jun. 2016 